\title{
Climatic change special issue: geoengineering research and its limitations
}

\author{
Robert Wood • Stephen Gardiner • \\ Lauren Hartzell-Nichols
}

Received: 30 October 2013 / Accepted: 30 October 2013

(C) Springer Science+Business Media Dordrecht 2013

\section{Background and motivation}

Even under scenarios that assume that humanity will move aggressively away from fossil fuels as the predominant source of energy for the world economy, the equivalent carbon dioxide concentration in the atmosphere is expected to at least double its preindustrial value by the end of this century. If reductions are not aggressive, or if emissions continue their rapid upward trend, then a tripling is likely, and perhaps even a quadrupling by early in the $22^{\text {nd }}$ century. Under such emission scenarios, it is likely that the global average temperature will come to exceed levels that numerous experts say will greatly harm ecosystems and human health, security and welfare. Given continuing political inertia surrounding global emissions reductions, such an outcome is becoming more and more difficult to avoid; indeed, at this point, some believe it inevitable if climate policy confines itself to conventional methods, such as mitigation and adaptation.

In this context, discussion of "geoengineering"-roughly the "deliberate large-scale manipulation of the planetary environment to counteract anthropogenic climate change" (Shepherd et al. 2009) - has become a hot topic. Proposed geoengineering approaches fall into two broad categories: those that attempt to limit solar radiation (termed solar radiation management, SRM) and those that attempt to remove carbon dioxide from the atmosphere (carbon drawdown and removal, CDR). A landmark study conducted by the United Kingdom's Royal Society ${ }^{1}$ in 2009 concluded that "geoengineering is likely to be technically feasible, and could substantially reduce the costs and risks of climate change". ${ }^{2}$ However, the report also maintained that not all proposed methods are likely to be equally effective, and that there is a need for further research to understand the feasibility, climate impacts and social dimensions (including ethics, law and governance) of proposed geoengineering schemes. One specific recommendation of the report was the need to "develop a code of practice for geoengineering research and provide recommendations to the international scientific community for a voluntary research governance

\footnotetext{
${ }^{1}$ Geoengineering the climate: science, governance and uncertainty. John Shepherd (Ed.), 2009. The Royal Society. Available at http://royalsociety.org/Geoengineering-the-climate/

${ }^{2}$ For an ethical analysis of the report, see Gardiner 2011.
}

R. Wood $(\bowtie) \cdot$ S. Gardiner $\cdot$ L. Hartzell-Nichols

University of Washington, Seattle, WA, USA

e-mail: robwood@atmos.washington.edu 
framework ... [that] should provide guidance and transparency for geoengineering research and apply to researchers working in the public, private and commercial sectors."

With these developments in mind, we convened an interdisciplinary group of international experts in the field of geoengineering science, climate modeling, environmental ethics, governance, policy, and law, to address the Royal Society's call for the development of a geoengineering research framework. (This work was supported through a grant from the University of Washington College of the Environment. ${ }^{3}$ ) The project consisted of two phases. The first involved a 10 -week interdisciplinary research seminar series entitled "Geoengineering: Science, Ethics and Policy" held at the University of Washington during January-March 2011. ${ }^{4}$ This series consisted of a sequence of public lectures and small-group discussions with leading international figures from the early debate about geoengineering. Its aims were to bring sophisticated discussion of the issue to a broad interdisciplinary audience on campus and beyond, and also to facilitate the development of cross-disciplinary connections between faculty, students and those involved in policy.

The second phase of the project was to produce a coordinated and interdisciplinary set of research papers on the theme of geoengineering research. This phase involved a focused interdisciplinary workshop and public debate between two leading figures-David Keith and Steve Rayner - at the University of Washington in April 2012. It culminates in this special issue. The papers presented attempt to address questions associated with the purpose and need for geoengineering research, the direction it should take, how it should be structured and governed, the need for broad public engagement in the research, its ethical implications, and whether and how field testing can be a useful component.

\section{Special issue papers}

Economics is becoming an increasingly important component of the debate on climate change, as is evident from the controversies about cost-benefit analyses of mitigation and adaptation. ${ }^{5}$ The first of our special issue papers (Juan Moreno-Cruz and David Keith) discusses the application of a simple economic model to explore how uncertainties in both SRM geoengineering and climate responses to greenhouse gases (GHGs) can be used to make decisions about economic impacts. One of its primary conclusions is that even modest reductions in the uncertainties about potential side-effects of SRM could significantly reduce the overall cost of climate change by making it easier to reach decisions on SRM deployment. The paper thus makes a case for increased knowledge about geoengineering approaches.

The next two papers take up the call for increased scientific knowledge and examine strategies to provide information about both the efficacy of geoengineering approaches and also their potential side effects. Alan Robock and colleagues discuss using existing analogs for both stratospheric sulfur SRM (volcanoes) and marine cloud brightening SRM (brightened regions in low clouds from commercial ships) that can provide useful information. In particular, such analogs can be used to test and improve models, and to sharpen our climate observing technologies. Robert Wood and Tom Ackerman take this one step further and argue that field testing marine cloud brightening over a limited area (order $100 \times 100 \mathrm{~km}$ ) would provide a critical test of marine cloud brightening to test models. Such an approach would also

\footnotetext{
3 http://coenv.washington.edu/

${ }^{4}$ A list of speakers, seminar titles and associated materials can be found at www.atmos.washington.edu/ $\sim$ robwood/Geoengineering

${ }^{5}$ E.g., Stern 2007; Nordhaus 2009; Gardiner 2011; Broome 2012.
} 
have an important side benefit of providing critical information about the interactions between aerosols and clouds that today remains one of the major uncertainties in our climate change projections. In addition, Wood and Ackerman maintain that the bar for success in such experiments is necessarily higher than that in conventional field studies, and argue that experiment design needs to consider climatic impacts, governance and ethics.

The next two papers explore the application of SRM in conjunction with GHG reductions. Detlef Van Vuuren explores the consequences of both SRM and rapid GHG mitigation on temperature and other aspects of the climate system, highlighting potential societal impacts. This work emphasizes that there are important differences in timescale associated with the two approaches. On the one hand, SRM works quickly to mitigate temperature impacts, whereas even rapid GHG emission reductions take decades to impact temperature. On the other hand, SRM alone cannot mitigate all deleterious impacts of climate change. Steven Smith and Philip Rasch use a scenario model to ask how much SRM will be needed to maintain global temperatures under a given threshold. The authors come to the important conclusion that, given a policy of jointly reducing GHG emissions and introducing SRM, the amounts of SRM needed to maintain temperatures below $2{ }^{\circ} \mathrm{C}$ above preindustrial levels are lower than those assumed in most modeling studies. Although SRM alone is unlikely to be sufficient for tackling the climate change problem, both papers make a case that scenarios in which SRM forms a component of a future approach are worth considering.

Steve Rayner and colleagues present and elaborate on their "Oxford Principles" for geoengineering governance. These five high-level principles have been very influential in early discussions of geoengineering policy, influencing the UK Government and the Asilomar conference among others. They maintain that geoengineering is to be regulated as a public good, and that there should be public participation in decision-making, disclosure of research and open publication of results, independent assessment of impacts, and development of governance before deployment. In the current paper, the authors clarify the motivations behind, social values embodied in, and functions of the principles. They also propose a structure for developing guidelines for specific geoengineering technologies.

Stephen Gardiner's paper raises worries about framing geoengineering as a "global public good" in the technical senses familiar from international relations theory and economics. He argues that the paradigmatic case of SRM, stratospheric sulfate injection, does not fit well with the canonical account of such goods, especially as manifested in the paradigm example of a lighthouse. More importantly, he suggests that the global public good framing is misleading, especially in the way it tends to marginalize ethical concerns. Hence, Gardiner concludes, more work is required on understanding the conditions under which geoengineering might be permissible, and on how it should be framed in public discussion.

In his paper, Dale Jamieson offers an overview of important attractions of geoengineering and some reasons for concern, including the problems of declaring an emergency, moral hazards, arrogance, silver bullets, and governance. Jamieson also suggests that the term 'geoengineering' does not really capture a distinct category of possible human response to climate change, but rather "expresses the suspicion of a speaker towards responses that she sees as in some way novel, weird, exotic, unfamiliar, or untested". Despite these worries, he concludes that some research on SRM and CDR should go on, but as part of a general portfolio of climate-related research, competing with the full range of other approaches, rather than as a dedicated research program of its own with separate funding.

Daniel Bodansky emphasizes that governing of geoengineering is not a one dimensional challenge, but involves many different tasks, some of which "seem more do-able than others". These tasks range from developing norms for scientific research to instituting procedures to prevent international conflict over deployment. Bodansky also identifies contrasting goals of 
geoengineering governance. Some are most concerned with facilitating research, to keep the door open for deployment; others focus on the potential risks, and so see governance as important for setting limits. In light of these different goals and tasks, the paper analyses the forms, objects and agents of governance by focusing on four scenarios of concern: inadequate research funding, premature rejection, unilateral individual action, and unilateral state action.

Lisa Dilling and Rachel Hauser focus on the question of how to govern geoengineering research. They suggest that there are three major categories of concern: the physical risks and impacts; transparency in decision-making and responsibility; and the "meaning" or implications of the research. An effective governance framework, they claim, should address each category. Moreover, they propose a "bottom up" approach that involves researchers and funding agencies working together in a "collaborative experiment" to develop norms and best practices in an evolving process.

In the final paper, Wylie Carr and colleagues explore the important idea of public participation in geoengineering decision-making, focusing on solar radiation management. They consider both why and how public participation might contribute to governance, in terms of fulfilling ethical requirements, enhancing trust, and incorporating a broad range of social interests, values and framings. In particular, they argue that open and inclusive deliberation is a moral imperative, because the leading alternatives, such as allowing decisions to be made solely by scientists and policy makers in a small group of countries, are unacceptable.

Any collection of papers in a fast-moving discipline can only represent a snapshot of viewpoints at a given period. We have attempted to focus primarily on the question of geoengineering research and the opportunities and challenges that may lie ahead should interest in geoengineering continue to grow. There are of course notable gaps. For example, where discussion focuses upon specific approaches, it mostly centers on solar radiation management with little explicit attention to carbon drawdown and removal. Yet the latter certainly requires attention as arguably it presents a somewhat different set of technical, ethical and governance challenges. We do believe, however, that this special issue provides the kind of diverse, cross-disciplinary discussion that is needed in this rapidly evolving, societally important, and often controversial field.

\section{References}

Broome J (2012) Climate matters. Norton, New York, NY

Gardiner S (2011) A perfect moral storm. Oxford University Press, New York, NY

Nordhaus W (2009) A question of balance. Yale University Press, New Haven

Stern N (2007) The economics of climate change. Cambridge University Press, Cambridge 